\title{
. ESTUDOS SÔBRE A NUTRIÇÃO MINERAL DO FEIJOEIRO (PHASEOLUS VULGARIS L., VAR. ROXINHO) *
}

\author{
A. Cobra Netto \\ W. R. ACCORSI \\ E. Malavolta
}

\section{RESUMO}

\begin{abstract}
No presente trabalho foi estudada a marcha de absorção de macronutrientes pelo feijoeiro (Phaseolus vulgaris L., var. roxinho) em condições de campo. Verificou-se que a produção mais alta de matéria sêca ocorreu quando as plantas tinham 56 dias de idade, o que corresponde aproximadamente a dois terços do período necessário para completar o ciclo. As quantidades totais de macronutrientes absorvida em $\mathrm{kg} / \mathrm{ha}$ foram: N-101, P-9, K-93, Ca-54, Mg-18 e S-25.

Em outro experimento foram obtidos, cultivando-se as plantas em solução nutritiva, sintomas típicos de carência dos macronutrientes estudados. Cortes anatômicos das fôlhas mostraram que a omissão dos elementos do substrato causava lesões nos tecidos, sendo os cloroplastos as organelas particularmente afetadas. Os seguintes níveis foliares de elementos caracterizam deficiência dos mesmos nas condições experimentais: $\mathrm{N}-1,54 \%, \mathrm{P}-0,13 \%, \mathrm{~K}-0,93 \%, \mathrm{Ca}-0,42 \%, \mathrm{Mg}-0,48 \%, \mathrm{~S}-0,70 \%$.
\end{abstract}

\section{INTRODUÇÃO}

O feijão constitui a fonte mais importante de proteína vegetal para a alimentação do povo brasileiro, motivo pelo qual é cultivado em todo o território nacional. A produção média por hectare no período 1967/1969 baixou de 698 para $606 \mathrm{~kg} / \mathrm{ha}$; não tendo havido variação na área cultivada pode-se concluir que a produtividade dessa leguminosa alimentícia caiu com a taxa de quase $5 \%$ ao ano no período considerado.

Ao fazer uma revisão da literatura nacional sobre a nutrição e a adubação do feijoeiro, MALAVOLTA (1971) concluiu que, além do problema possivelmente maior relacionado à ecologia e de outros a

\footnotetext{
* Entregue para publicação em 21-12-1971. Parte da tese de doutoramento do primeiro autor apresentada à E.S.A. "Luiz de Queiroz" USP, Piracicaba, São Paulo.

** Departamento de Solos e Geologia - ESALQ-USP.

*** Departamento de Botânica - ESALQ-USP.

***** Departamento de Química - ESALQ-USP.
} 
falta de adubação seria um fator limitante em diversas regiões do País. No trabalho em questão, além de uns poucos trabalhos básicos sobre marcha de absorção e diagnose foliar, foram analisados 177 experimentos de adubação, conduzidos no Amazonas, Pará, Minas Gerais, Goiás, D. Federal, São Paulo, Santa Catarina e Rio Grande do Sul; as respostas obtidas assim se resumem: Nitrogênio - 48, Fósforo - 77, Potássio - 14, Calagem - 22, Matéria Orgânica 23, Micronutrientes - 17 .

A importância econômica da cultura, de um lado e o pequeno número de estudos básicos de outro, justificam pois, a presente contribuição em que se pretendeu estudar: as quantidades de macronutrientes extraídas pelo feijoeiro em diversas épocas de desenvolvimento da planta; os efeitos das deficiencias minerais no crescimento, composição química; obter um quadro sintomatológico e das variações anatômicas provocados pe a omissão de macronutrientes.

\section{MATERIAL E MÉTODOS}

\subsection{Variedade}

Foi utilizada a variedade "roxinho" cujas sementes foram previamente desinfectadas com "Abavit-Novo".

\subsection{Ensaio de campo}

3.2.1. O experimento foi instalado em solo da série "Luiz de Queiroz" (RANZANI et al., 1966) cujas características químicas se encontram na Tabela 1.

TABELA 1. - Características da terra em que foi instalado o ensaio de campo.

\begin{tabular}{ll}
\hline $\mathrm{pH}$ & 6,1 \\
Matéria orgânica \% & 2,06 \\
Nitrogênio $(\mathrm{N}) \%$ & 0,16 \\
$\mathrm{PO}_{4} \cdots \mathrm{e} . \mathrm{mg} / 100 \mathrm{~g}$ de solo & 0,15 \\
$\mathrm{~K}+$ trocável e. $\mathrm{mg} / 100 \mathrm{~g}$ de solo & 0,40 \\
$\mathrm{Ca}+$ trocável e. $\mathrm{mg} / 100 \mathrm{~g}$ de solo & 3,00 \\
$\mathrm{Mg}++$ trocável e. $\mathrm{mg} / 100 \mathrm{~g}$ de solo & 1,00 \\
$\mathrm{H}+$ trocável e. $\mathrm{mg} / 100 \mathrm{~g}$ de solo & 4,90
\end{tabular}


3.2.2 A área do ensaio foi dividida em duas parcelas de $10 \mathrm{x}$ $20 \mathrm{~m}$; entre as linhas usou-se o espaçamento de $0,4 \mathrm{~m}$; nos sulcos foram aplicados $500 \mathrm{~kg}$ de superfosfato simples, 200 de cloreto de potássio por hectare e $100 \mathrm{~kg}$ de nitrocálcio de Cubatão; 20 dias após a semeadura foram aplicados em cobertura $200 \mathrm{~kg}$ de nitrocálcio/ha.

3.2.3 Em cada uma das duas parcelas foram colhidas 100 plantas ao acaso nas seguintes épocas:

Dias após a semeadura

5 a 8
15
20
25
34

37
46
56
66

77

Estado fisiológico da cultura

Germinação

$1 .^{\mathrm{a}}$ amostragem, 1.a folha composta aberta

Aplicação do nitrogênio em cobertura

2. ${ }^{a}$ amostragem. Planta formada com 3 a 4 folhas compostas

3. amostragem. Plantas apresentando botões florais

Início do florescimento

4. ${ }^{\mathrm{a}}$ amostragem. Máximo de floração

5. amostragem. Final de floração e vagens formadas

$6 .^{a}$ amostragem. Vagens maduras e queda das folhas

7. amostragem. Vagens e plantas na maioria secas e com poucas folhas

As amostras tiveram suas raízes lavadas com $\mathrm{HCl} 0,2 \mathrm{~N}$ e depois com água destilada; seguiu-se a separação das diversas partes, a pesagem do material fresco e, em seguida, tomou-se o peso seco a $70^{\circ} \mathrm{C}$.

\subsection{Ensaio em casa de vegetação}

3.3.1. Usou-se um delineamento experimental em blocos inteiramente casualizados com 3 repetições; cada repetição consistiu de 4 plantas por litro de solução de HOAGLAND \& ARNON (1950) modificada de acordo com os tratamentos seguintes:

Tratamentos

$$
\begin{gathered}
\text { Completo } \\
-\mathrm{N} \\
-\mathrm{P} \\
-\mathrm{K} \\
-\mathrm{Ca} \\
-\mathrm{Mg} \\
-\mathrm{S}
\end{gathered}
$$

\section{Soluções}

Completa (macronutrientes + micronutrientes)

Com omissão de nitrogênio

Com omissão de fósforo

Com omissão de potássio

Com omissão de cálcio

Com omissão de magnésio

Com omissão de enxôfre 
3.3.2 A colheita das plantas se fez quando as mesmas começavam a mostrar sintomas de carência; o procedimento usado foi o descrito em 3.2.3.

Os sintomas visuais foram anotados; as alterações anatômicas foram examinadas em cortes à mão livre procedidas nos folíolos.

\subsection{Análise química e análise estatística}

Foram procedidas por métodos convencionais.

\section{RESUlTAdOS E DISCUSSÃo}

\subsection{Ensaio de campo}

4.1.1 A Tabela 4.1 resume a marcha de produção da matéria seca por 100 plantas. Foi obtido um coeficiente de correlação significativo a $1 \%$ de probabilidade entre peso fresco e peso seco $(\mathrm{r}=$ $0,965)$.

Pode-se observar que a produção de matéria seca atingiu o seu máximo aos 56 dias, ou seja, quando as plantas completaram aproximadamente $2 / 3$ do seu ciclo; esse período coincide com o final da floração e formação de vagens.

TABELA 4.1. - Material sêco produzido nas diversas partes e idades do feijoeiro. Pêso médio da matéria seca de 100 plantas em $\mathrm{g}$.

\begin{tabular}{crrrrrr}
\hline $\begin{array}{c}\text { Idade da } \\
\text { planta em } \\
\text { dias }\end{array}$ & Raiz & Caule & Fôlha & Flor & Vagem & total \\
\hline 15 & 2,1 & 5,0 & 16,7 & - & - & 23,8 \\
25 & 8,0 & 16,7 & 68,8 & - & - & 93,5 \\
34 & 23,7 & 55,8 & 220,8 & - & - & 300,3 \\
46 & 33,7 & 129,9 & 327,9 & 19,7 & - & 511,2 \\
56 & 39,5 & 205,5 & 597,5 & 8,4 & 97,2 & 948,1 \\
66 & 30,6 & 155,8 & 155,6 & - & 271,2 & 613,2 \\
77 & 32,1 & 160,0 & 29,3 & - & 489,9 & 711,3 \\
\hline
\end{tabular}


4.1.2. As Tabelas 4.2 e 4.3 dão respectivamente a concentração de macronutrientes nas plantas em função da época de amostragem e as quantidades totais calculadas por hectare (250.000 plantas e produção de $1 \mathrm{t} / \mathrm{ha}$ ).

TABELA 4.2. - Teores médios dos macronutrientes na matéria seca das plantas.

\begin{tabular}{|c|c|c|c|c|c|c|c|}
\hline \multirow{2}{*}{$\begin{array}{l}\text { Dias } \\
\text { após o } \\
\text { plantio }\end{array}$} & \multirow{2}{*}{$\begin{array}{l}\text { Parte da } \\
\text { planta }\end{array}$} & \multirow[b]{2}{*}{ N\% } & \multicolumn{5}{|c|}{ Nutrientes } \\
\hline & & & $\mathrm{P} \%$ & $\mathrm{~K} \%$ & $\mathrm{Ca} \%$ & $\mathrm{Mg} \%$ & $\mathrm{~S} \%$ \\
\hline \multirow{3}{*}{15} & Raiz & 3,22 & 0,31 & 3,05 & 1,10 & 0,57 & 0,76 \\
\hline & Caule & 3,29 & 0,47 & 4,82 & 1,78 & 0,48 & 0,89 \\
\hline & Folha & 4,69 & 0,44 & 3,87 & 1,99 & 0,54 & 0,59 \\
\hline \multirow{3}{*}{25} & Raiz & 2,95 & 0,28 & 2,47 & 1,20 & 0,33 & 0,68 \\
\hline & Caule & 2,90 & 0,22 & 4,55 & 1,92 & 0,29 & 0,71 \\
\hline & Folha & 4,48 & 0,27 & 3,65 & 2,92 & 0,57 & 0,64 \\
\hline \multirow{3}{*}{34} & Raiz & 2,10 & 0,15 & 2,17 & 0,98 & 0,22 & 0,67 \\
\hline & Caule & 2,38 & 0,21 & 3,82 & 1,34 & 0,25 & 0,78 \\
\hline & Folha & 3,76 & 0,32 & 3,12 & 2,82 & 0,39 & 0,59 \\
\hline \multirow{4}{*}{46} & Raiz & 1,61 & 0,11 & 2,10 & 1,72 & 0,21 & 0,83 \\
\hline & Caule & 1,61 & 0,19 & 3,02 & 1,06 & 0,26 & 0,95 \\
\hline & Folha & 3,36 & 0,35 & 2,70 & 3,28 & 0,33 & 0,56 \\
\hline & Flôr & 4,13 & 0,80 & 3,62 & 1,04 & 0,34 & 0,57 \\
\hline \multirow{5}{*}{56} & Raiz & 1,75 & 0,15 & 1,80 & 1,83 & 0,43 & 0,96 \\
\hline & Caule & 1,68 & 0,11 & 2,10 & $1 ; 60$ & 0,24 & 0,71 \\
\hline & Folha & 3,57 & 0,30 & 3,82 & 2,64 & 0,76 & 0,74 \\
\hline & Flôr & 3,71 & 0,70 & 4,87 & 1,40 & 0,70 & 0,89 \\
\hline & Vagem & 4,06 & 0,43 & 2,90 & 1,38 & 0,43 & 0,65 \\
\hline \multirow{4}{*}{66} & Raiz & 1,36 & 0,05 & 2,17 & $.1,44$ & 0,59 & 0,96 \\
\hline & Caule & 1,54 & 0,08 & 1,92 & 0,88 & 0,57 & 0,82 \\
\hline & Folha & 3,01 & 0,16 & 2,67 & 2,58 & 0,63 & 0,81 \\
\hline & Vagem & 2,76 & 0,27 & 1,95 & 0,52 & 0,41 & 0,71 \\
\hline \multirow{4}{*}{77} & Raiz & 1,98 & 0,02 & 1,70 & 1,58 & 0,59 & 0,96 \\
\hline & Caule & 1,67 & 0,04 & 1,92 & 1,34 & 0,56 & 0,78 \\
\hline & Folha & 2,87 & 0,15 & 1,60 & 2,96 & 0,66 & 0,74 \\
\hline & Vagem & 3,04 & 0,29 & 1,80 & 0,36 & 0,36 & 0,77 \\
\hline
\end{tabular}


TABELA 4.3. - Quantidades de macronutrientes na matéria seca. das plantas em $\mathrm{kg} / \mathrm{ha}$.

\begin{tabular}{|c|c|c|c|c|c|c|c|}
\hline \multirow{2}{*}{$\begin{array}{l}\text { Dias } \\
\text { após o } \\
\text { plantio }\end{array}$} & \multirow{2}{*}{$\begin{array}{l}\text { Partes da } \\
\text { planta }\end{array}$} & \multirow[b]{2}{*}{$\mathbf{N}$} & \multicolumn{5}{|c|}{ Nutrientes em $\mathrm{kg} / \mathrm{ha}$} \\
\hline & & & $\mathbf{P}$ & $\mathrm{K}$ & $\mathrm{Ca}$ & $\mathrm{Mg}$ & $\mathbf{S}$ \\
\hline 15 & $\begin{array}{l}\text { Raiz } \\
\text { Caule } \\
\text { Folha } \\
\text { Total }\end{array}$ & $\begin{array}{l}0,169 \\
0,411 \\
1,749 \\
2,329\end{array}$ & $\begin{array}{l}0,016 \\
0,059 \\
0,187 \\
0,262\end{array}$ & $\begin{array}{l}0,160 \\
0,602 \\
1,615 \\
2,377\end{array}$ & $\begin{array}{l}0,058 \\
0,222 \\
0,830 \\
1,100\end{array}$ & $\begin{array}{l}0,030 \\
0,060 \\
0,227 \\
0,317\end{array}$ & $\begin{array}{l}0,040 \\
0,112 \\
0,248 \\
0,400\end{array}$ \\
\hline 25 & $\begin{array}{l}\text { Raiz } \\
\text { Caule } \\
\text { Folha } \\
\text { Total }\end{array}$ & $\begin{array}{l}0,590 \\
1,210 \\
7,706 \\
9,506\end{array}$ & $\begin{array}{l}0,056 \\
0,095 \\
0,466 \\
0,617\end{array}$ & $\begin{array}{l}0,494 \\
1,899 \\
6,278 \\
8,671\end{array}$ & $\begin{array}{l}0,240 \\
0,801 \\
5,022 \\
6,063\end{array}$ & $\begin{array}{l}0,066 \\
0,124 \\
0,992 \\
1,182\end{array}$ & $\begin{array}{l}0,137 \\
0,298 \\
1,109 \\
1,554\end{array}$ \\
\hline 34 & $\begin{array}{l}\text { Raiz } \\
\text { Caule } \\
\text { Folha } \\
\text { Total }\end{array}$ & $\begin{array}{r}1,244 \\
3,320 \\
20,755 \\
25,319\end{array}$ & $\begin{array}{l}0,091 \\
0,298 \\
1,777 \\
2,166\end{array}$ & $\begin{array}{r}1,286 \\
5,329 \\
17,222 \\
23,837\end{array}$ & $\begin{array}{r}0,581 \\
1,869 \\
15,566 \\
18,016\end{array}$ & $\begin{array}{l}0,131 \\
0,351 \\
2,197 \\
2,679\end{array}$ & $\begin{array}{l}0,397 \\
1,092 \\
3,284 \\
4,773\end{array}$ \\
\hline 46 & $\begin{array}{l}\text { Raiz } \\
\text { Caule } \\
\text { Folha } \\
\text { Flôr } \\
\text { Total }\end{array}$ & $\begin{array}{r}1,356 \\
5,228 \\
30,904 \\
2,034 \\
39,522\end{array}$ & $\begin{array}{l}0,094 \\
0,643 \\
3,256 \\
0,395 \\
4,388\end{array}$ & $\begin{array}{r}1,769 \\
9,807 \\
24,833 \\
1,782 \\
38,191\end{array}$ & $\begin{array}{r}1,449 \\
3,442 \\
30,167 \\
0,512 \\
35,570\end{array}$ & $\begin{array}{l}0,184 \\
0,860 \\
3,044 \\
0,170 \\
4,258\end{array}$ & $\begin{array}{l}0,706 \\
3,114 \\
5,205 \\
0,282 \\
9,307\end{array}$ \\
\hline 56 & $\begin{array}{l}\text { Raiz } \\
\text { Caule } \\
\text { Folha } \\
\text { Flor } \\
\text { Vagem } \\
\text { Total }\end{array}$ & $\begin{array}{r}1,728 \\
8,631 \\
53,327 \\
0,779 \\
9,866 \\
74,331\end{array}$ & $\begin{array}{l}0,153 \\
0,575 \\
4,601 \\
0,147 \\
1,045 \\
6,521\end{array}$ & $\begin{array}{r}1,777 \\
10,789 \\
57,061 \\
1,023 \\
7,047 \\
77,697\end{array}$ & $\begin{array}{r}1,807 \\
8,220 \\
39,435 \\
0,294 \\
3,353 \\
53,109\end{array}$ & $\begin{array}{r}0,426 \\
1,258 \\
11,487 \\
0,149 \\
1,047 \\
14,367\end{array}$ & $\begin{array}{r}0,948 \\
3,668 \\
11,069 \\
0,187 \\
1,579 \\
17,451\end{array}$ \\
\hline 66 & $\begin{array}{l}\text { Raiz } \\
\text { Caule } \\
\text { Folha } \\
\text { Vagem } \\
\text { Total }\end{array}$ & $\begin{array}{r}1,040 \\
5,998 \\
11,709 \\
18,713 \\
37,460\end{array}$ & $\begin{array}{l}0,042 \\
0,327 \\
0,653 \\
1,837 \\
2,859\end{array}$ & $\begin{array}{r}1,660 \\
7,478 \\
10,386 \\
13,221 \\
32,745\end{array}$ & $\begin{array}{r}1,101 \\
3,428 \\
10,036 \\
3,526 \\
18,091\end{array}$ & $\begin{array}{r}0,457 \\
22,247 \\
2,451 \\
2,786 \\
7,941\end{array}$ & $\begin{array}{r}0,735 \\
3,209 \\
3,151 \\
4,841 \\
11,936\end{array}$ \\
\hline 77 & $\begin{array}{l}\text { Raiz } \\
\text { Caule } \\
\text { Folha } \\
\text { Vagem } \\
\text { Total }\end{array}$ & $\begin{array}{r}1,589 \\
6,680 \\
2,102 \\
37,232 \\
47,603\end{array}$ & $\begin{array}{l}0,022 \\
0,176 \\
0,110 \\
3,662 \\
3,970\end{array}$ & $\begin{array}{r}1,364 \\
7,680 \\
1,172 \\
22,045 \\
32,261\end{array}$ & $\begin{array}{r}1,268 \\
5,360 \\
2,168 \\
4,409 \\
13,205\end{array}$ & $\begin{array}{l}0,479 \\
2,252 \\
0,486 \\
4,458 \\
7,676\end{array}$ & $\begin{array}{r}0,771 \\
3,120 \\
0,543 \\
9,528 \\
13,962\end{array}$ \\
\hline
\end{tabular}

Os dados obtidos concordam, em linhas gerais com as de GALLO \& MIYASAKA (1961) e HAAG et al. (1967).

4.3. Para fins de adubação é útil o que apresenta a Tabela 4.4. Verifica-se que, quanto à absorção, os macronutrientes se dispõem na seguinte ordem decrescente:

$\mathrm{N} \quad \mathrm{K} \quad \mathrm{Ca} \quad \mathrm{S} \quad \mathrm{Mg} \quad \mathrm{P} \quad$;

A exportação, entretanto, obedece à ordem: 


$$
\mathrm{N} \quad \mathrm{K} \quad \mathrm{S} \quad \mathrm{P}=\mathrm{Ca}=\mathrm{Mg} ;
$$

porcentualmente tem-se em números redondos os seguintes índices de exportação:

$\begin{array}{ll}\mathrm{N} & 30 \% \\ \mathrm{P} & 50 \\ \mathrm{~K} & 20 \\ \mathrm{Ca} & 10 \\ \mathrm{Mg} & 25 \\ \mathrm{~S} & 40 ;\end{array}$

esses índices relativamente baixos de exportação combinados com suprimentos médios nos solos brasileiros ajudam a explicar, em parte pelo menos, a ausência de resposta ao uso de alguns elementos e mesmo o efeito depressivo da sua adição, conforme relatado por MALAVOLTA (1971).

TABELA 4.4. - Absorção e exportação de macronutrientes pelo amendoim.

\begin{tabular}{ccc}
\hline Elemento & Absorvido & $\mathrm{kg} / \mathrm{ha}$ \\
N & 102 & 37 \\
P & 9 & 4 \\
K & 93 & 22 \\
Ca & 54 & 4 \\
Mg & 18 & 4 \\
S & 25 & 10 \\
\hline
\end{tabular}

\subsection{Ensaio em casa-de-vegetação}

\subsubsection{Sintomas de deficiencia}

\subsubsection{Nitrogênio}

Observou-se uma clorose nos folíolos, a princípio nas folhas mais velhas. As nervuras de várias ordens, embora hialinas, tornaram-se mais destacadas do fundo. Com o evoluir dos sintomas a clorose se assentou permanecendo, entretanto, numerosas manchas punctiformes, pequeninas, como salpicos verdes. Nessa fase, surgiram áreas esbranquiçadas em várias partes do limbo e que foram aos poucos aumentando em superfície.

Os sintomas obtidos concordam de um modo geral com os descritos em DESAI (1937) e WALLACE (1961, pág. 85). 
As alterações mais evidentes que a deficiência de $\mathbf{N}$ provocou nas células do mesófilo ocorreram nos cloroplastos e inicialmente se apresentaram como um descoramento da cor verde característica. Com o evoluir dos sintomas, tanto nas células do paliçádico como nas do lacunoso, em lugar dos cloroplastos apareceram numerosos grânulos, de tamanhos vários, com formas diversas, de bastonetes, bacilares, fusiformes, etc., sendo que os menores apresentavam movimento browniano. Todos eles estavam completamente descorados, daí as áreas esbranquiçadas que apareceram no limbo. As mencionadas granulações reagiram com o amido quando tratadas com o reativo de lugol.

\subsubsection{Fósforo}

As plantas vegetando em solução da qual foi omitido o $\mathrm{P}$ apresentavam os folíolos novos de coloração verde azulada, sendo que os mais velhos se mostraram de um verde mais claro. Os caules se tornavam mais curtos e mais finos enquanto que as raízes, embora mais finas, aparentemente não diferissem, em volume, das raízes das plantas cultivadas em solução completa. As fôlhas cotiledonares caíam prematuramente. O desenvolvimento da parte aérea, como um todo, era reduzido.

Os folíolos das fôlhas mais velhas exibiam sintomas de deficiencia em vários graus de intensidade. Estes surgiam a princípio, como áreas internervais cloróticas, algumas das quais com pequenas pontuações marrons principalmente nos bordos da porção terminal do limbo que, nesse estágio, começaram a se enrolar. $\mathrm{Na}$ fase aguda da deficiencia, os folíolos adquiriram coloração pardacenta com manchas escuras e pontuações generalizadas; o limbo enrolado para cima desprendia-se necrosado.

Os sintomas descritos apresentavam desenvolvimento ascendente.

De um modo geral os sintomas obtidos concordam com os descritos por DESAI (1937) e WALLACE (1961, pág. 85).

A deficiencia de $\mathbf{P}$ afetava principalmente os cloroplastos mais os do tecido paliçádico que os lacunoso. $\mathrm{O}$ exame do mesófilo, na região da clorose internerval mostrava os cloroplastos do paliçádico esmaecidos, de forma irregular, aglutinados em número variável, com forma de rosário arqueado. Outros permaneciam isolados e alguns continuavam com aspecto normal. Em determinados trechos ocorriam aglomerações de cloroplastos à semelhança de cachos de uva.

\subsubsection{Potássio}

As plantas deficientes em $\mathrm{K}$ apresentavam crescimento reduzido, os caules eram finos e as raízes em menor quantidade que nas plantas 
testemunhas. Os folíolos apresentavam-se reduzidos e os sintomas eram mais evidentes nos mais velhos.

Os sintomas de carência eram mais pronunciados na primeira fôlha composta após as primordias. Manifestavam-se, a princípio, na extremidade dos folíolos, como manchas de tonalidades de acinzentada, de tamanhos diversos, irregulares, em pleno processo de necrose. Ao exame estereoscópico, verificava-se que a epiderme, na área das manchas, era finamente estriada. As pontas dos folíolos se curvavam na página superior.

Em fôlhas mais desenvolvidas, além da clorose, surgiram inúmeras pequeninas pontuações, bem próximas entre si, causando a impressão de retículo. Da associação dessas manchinhas formavam-se outras grandes, de côr pardo-escuro, já em fase de necrose. Nestas fôlhas, também os folíolos estavam com suas pontas viradas para a página superior.

Os sintomas encontrados concordam com os descritos em DESAI (1937), COBRA (1963) e ULRICH e OHKI (1966).

Para o exame das alterações histológicas provocadas pela carência de $K$, executaram-se cortes transversais no limbo dos folíolos, abrangendo as áreas cloróticas salpicadas de pequeninas manchas marrons. As observações microscópicas revelaram alterações estruturais nos cloroplastos, afetando a côr, a forma, o tamanho e a distribuição no campo celular. Assim, nas imediações das áreas cloróticas, os cloroplastos já se mostravam um tanto esmaecidos, conservando, porém, a forma. Os da área clorótica eram bem amarelecidos, menores e de forma globular. Os tecidos, por sua vez, eram menos consistentes com células deformadas, de membranas contraídas. Nos espaços intercelulares ou nos meatos havia acúmulo de gases e a região se tornava sombreada. Notava-se, ainda, que as pequenas pontuações marrons ou ferrugíneas do limbo resultavam das modificações sofridas pelas células epidérmicas e do parênquima paliçádico, cujo conteúdo adquiria coloração marrom e seus cloroplastos se desorganizavam. As manchas maiores mostravam as mesmas alterações, mais acentuada, porém, a fase final dêsse processo era a necrose.

\subsubsection{Cálcio}

As plantas, sob tratamento com omissão de $\mathrm{Ca}$, mostravam pequenas quantidades de raízes e caules mal desenvolvidos.

Apesar de as plantas estarem bem afetadas pela carência de $\mathrm{Ca}$ até a data da colheita elas continuavam emitindo nova brotação, sem, contudo, mostrar nas partes novas, sintomas de deficiência. 
No que se refere aos sintomas foliares, as fôlhas inferiores mostravam-se com pequeninas manchas acinzentadas e, posteriormente, eram afetadas de clorose parcial intensa que se iniciava na base dos folíolos e se propagava por entre as nervuras, em graus diversos de penetração, resultando daí formas de contôrno irregular para a porção do limbo que se mantinha verde.

Sôbre as áreas cloróticas surgiam manchas pardas, irregulares, de vários tamanhos, as quais podem ser consideradas como sintomas secunáários. Os folíolos, ao atingirem êsse estágio de deficiência se desprendiam da planta.

Os sintomas encontrados concordam com os descritos em WALLACE (1961, pág. 86) e CHAPMAN (1966, pág. 68), porém discordam no que se refere ao aparecimento da nova brotação.

Procedendo-se ao exame microscópico das estruturas constatouse que as alterações motivadas pela deficiência de $\mathrm{Ca}$ se refletiam, a princípio, nos cloroplastos, afetando-lhes a côr, e a forma e a distribuição na célula e, nos estágios mais avançados, verificou-se o mesmo fato até nos tecidos. Quanto à côr, observa-se uma clorose progressiva até a completa falta de clorofila, donde a presença de manchas cloróticas no limbo.

\subsubsection{Magnésio}

Os sintomas de carência ocorriam, inicialmente, nas fôlhas da porção inferior das plantas e a seguir, manifestavam-se nas superiores. Caracterizavam-se por uma clorose fraca, generalizada, menos junto às nervuras que permaneciam hialinas, onde o verde se mantinha à guiza de frise. Em conseqüência dessa disposição, a nervação se destacava do fundo esmaecido do limbo. Com o progredir dos sintomas, surgiam manchas pálidas, quase esbranquiçadas, pela lâmina foliar, de vários tamanhos e de conformação irregular. Em seguida, as manchas começavam a escurecer na região central denotando a presença de necrose, a qual se propagava para a periferia da mancha. Muitas manchas escuras se apresentavam aureoladas de branco. As fôlhas novas, superiores mostravam indícios de clorose. De um modo geral, a lâmina foliar se apresentava um tanto arqueada.

Os sintomas encontrados não apresentaram a coloração pardoavermelhadas nas fôlhas velhas, e, portanto, diferem em parte com os descritos por WALLACE (1961) e CHAPMAN (1966, pág. 228).

Das observações levadas a efeito em grande número de cortes praticados na área dos sintomas, constatou-se que, junto as nervuras, os cloroplastos eram de coloração verde normal e nas áreas afetadas pela carência êles se apresentavam cloróticas porém não tão acentuadamente como no caso da deficiencia de $\mathrm{Ca}$, ostentando uma tonalida- 
de verde esmaecida. De um modo geral, os cloroplastos se fragmentavam em numerosos grânulos que a princípio se conservavam unidos, e, posteriormente, se separavam, razão porque eram encontradas células cheias de granulações fusiformes com formas de bastonetes, quase brancas. Com o emprêgo do reativo de Lugol pode-se verificar a presença de amido nos cloroplastos mais esmaecidos bem como nos grânulos. No plastos das células estomáticas também se registrou a presença de amido. Os sintomas acima se acentuavam nas imediações das áreas mais alteradas e na região das manchas escuras os tecidos estavam desorganizados.

\subsubsection{Enxôfre}

Os sintomas foliares de carência de $\mathrm{S}$ eram mais evidentes nas fôlhas novas. De um modo geral, as fôlhas exibiam maior superfície do limbo que os das plantas normais. Os folíolos apresentavam clorose cuja intensidade variava de acôrdo com a época do aparecimento. Surgiram na região periférica dos folíolos, ora como manchas isoladas, de tamanho e contôrno diversos, ora reunidos formando extensas áreas amareladas. Encontravam-se às vezes sôbre algumas dessas áreas cloróticas, diminutas áreas necróticas, revelando a evolução dos sintomas. Em outras fôlhas a clorose era total e os folíolos se mostravam um tanto transparentes, realçando as nervuras, já um tanto claras, do fundo amarelado.

O exame microscópico dos cortes transversais da lâmina foliar, na área dos sintomas, revelou que as alterações principais, decorrentes da deficiência de $\mathrm{S}$ atingiam, principalmente os cloroplastos, tanto do paliçádico como do lacunoso, afetando-lhes o número, a forma $\mathrm{e}$ côr. Nas proximidades das nervuras notadamente da principal essas modificações eram menos pronunciadas, por isso que as nervuras se destacavam pela sua coloração esverdeada.

Os cloroplastos alterados estavam reunidos, via de regra, na região central da célula, predominando os tipos fusiformes, vindo com menos frequiência os tipos bastonetes e globulosos. Ocorriam, ainda, pequenas massas esverdeadas e formadas por alguns cloroplastos aglutinados.

Os trechos do mesófilo mais afastados das nervuras, onde, portanto, os sintomas eram mais pronunciados, possuiam cloroplastos profundamente alterados na forma, de tamanhos reduzidos, cloróticos, aglutinados em grande parte e que eram a causa das áreas cloróticas do limbo.

\subsubsection{Desenvolvimento das plantas}

O efeito dos tratamentos na produção de matéria sêca das diversas partes das plantas aparece na Tabela 4.5. 
Considerando-se apenas a produção total de matéria seca verificase que nos diversos tratamentos foi obedecida a seguinte ordem decrescente:

$$
\text { Completo }-\mathrm{S}-\mathrm{K}-\mathrm{Mg}-\mathrm{Ca}-\mathrm{P}-\mathrm{N} \text {; }
$$

tais dados refletem em grande parte a precocidade do aparecimento dos sintomas porquanto as plantas eram colhidas quando os mesmos se manifestavam.

TABELA 4.5. - Produção de matéria seca pelas partes da planta. Média de três repetições de 12 plantas cada uma.

\begin{tabular}{|c|c|c|c|c|c|}
\hline TRATAMENTOS & Raizes & $\begin{array}{l}\text { Partes } \\
\text { Caules }\end{array}$ & $\begin{array}{l}\text { vegeta } \\
\text { Fôlhas }\end{array}$ & $\begin{array}{l}\text { em g } \\
\text { Vagens }\end{array}$ & Total \\
\hline Macro + micronutrientes & 7,3 & 8,4 & 14,5 & 5,5 & 35,7 \\
\hline Omissão de nitrogênio & 3,0 & 2,0 & 3,5 & & 8,5 \\
\hline Omissão de fósforo & 3,1 & 2,1 & 4,1 & & 9,3 \\
\hline Omissão de potássio & 4,5 & 7,3 & 10,5 & 0,36 & 22,6 \\
\hline Omissão de cálcio & 2,1 & 2,6 & 6,4 & & 11,1 \\
\hline Omissão de magnésio & 3,4 & 4,8 & 11,9 & & 20,1 \\
\hline Omissão de enxôfre & 5,7 & 6,4 & 11,9 & 6,5 & 30,5 \\
\hline d.m.s. a $5 \%$ & 1,68 & 2,17 & 4,40 & & \\
\hline d.m.s. a $1 \%$ & 2,14 & 2,78 & 5,62 & & \\
\hline C.V. \% & 14,35 & 15,84 & 17,41 & & \\
\hline
\end{tabular}

\section{Concentração dos elementos nas fôlhas}

Na Tabela 4.6. estão representados os valores referentes à concentração dos macronutrientes nas fôlhas, bem como as transformações correspondentes em arc sen $\mathrm{x}$.

A concentração de nitrogênio nas fôlhas foi mais baixo no tratamento em que ele foi omitido da solução. Nos tratamentos $-\mathrm{Ca},-\mathrm{Mg}$, - $\mathrm{K}$ e - $\mathrm{P}$ foram superiores ao Completo ao nível de 5\%.

SUZUKI e KENDO (1936) em cana-de-açúcar, COBES e SAMUELS (1955) e HAAG (1958) em cafeeiro e HAAG (1965) em cana-de-açúcar também verificaram que a omissão de potássio eleva o teor de nitrogênio. Segundo EATON (1952), RICHARDS e BERNER (1954) as plantas deficientes em potássio aumentam a quantidade de ácidos aminados livres. Esta explicação encontra apoio nas teorias de RICHARDS e TEMPLEMAN (1936) e WALL (1939).

GILBERT (1951) encontrou que, em geral, as plantas deficientes em enxôfre se caracterizam por teores elevados de nitrogênio. NEAS (1953) observou maior teor de nitrogênio nas plantas de fumo que 
não receberam enxôfre. Os dados obtidos não apresentam concordância com os mencionados autores.

TABELA 4.6. - Concentração dos macronutrientes na fôlha.

\begin{tabular}{lcccccc}
\hline TRATAMENTOS & $\mathrm{N}$ & $\mathrm{P}$ & $\mathrm{K}$ & $\mathrm{Ca}$ & $\mathrm{Mg}$ & $\mathrm{S}$ \\
\hline Macro + micronutrientes & 2,61 & 0,36 & 4,45 & 4,01 & 0,86 & 0,81 \\
& $(9,29)$ & $(3,39)$ & $(12,18)$ & $(11,55)$ & $(5,32)$ & $(5,16)$ \\
Omissão de nitrogênio & 1,54 & 0,81 & 4,76 & 1,06 & 0,84 & 1,54 \\
& $(7,13)$ & $(5,18)$ & $(12,60)$ & $(5,90)$ & $(5,25)$ & $(7,11)$ \\
Omissão de fósforo & 4,24 & 0,13 & 5,90 & 2,77 & 0,63 & 0,75 \\
& $(11,89)$ & $(2,09)$ & $(14,06)$ & $(9,58)$ & $(4,56)$ & $(4,98)$ \\
Omissão de potássio & 3,64 & 0,53 & 0,93 & 5,09 & 0,95 & 0,84 \\
& $(10,97)$ & $(4,18)$ & $(5,54)$ & $(13,03)$ & $(5,60)$ & $(5,26)$ \\
Omissão de cálcio & 3,54 & 0,45 & 5,46 & 0,42 & 1,37 & 0,79 \\
& $(10,85)$ & $(3,85)$ & $(13,51)$ & $(3,70)$ & $(6,71)$ & $(5,11)$ \\
Omissão de magnésio & 3,59 & 0,50 & 6,86 & 2,92 & 0,48 & 0,78 \\
& $(10,92)$ & $(4,07)$ & $(15,19)$ & $(9,84)$ & $(3,99)$ & $(5,07)$ \\
Omissão de enxôfre & 2,70 & 0,35 & 5,46 & 4,18 & 0,87 & 0,70 \\
& $(9,46)$ & $(3,37)$ & $(13,53)$ & $(11,78)$ & $(5,36)$ & $(4,80)$ \\
\hline d.m.s. 5\% & 0,94 & 0,79 & 1,16 & 1,62 & 0,88 & 0,62 \\
C.V. \% & 3,3 & 7,5 & 3,3 & 6,1 & 5,9 & 4,1 \\
\hline
\end{tabular}

O tratamento - $\mathbf{P}$ apresentou alto teor de nitrogênio nas fôlhas. Este acúmulo também foi observado por CLEMENTS e outros (1941) em cana-de-açucar. A deficiência de fósforo em soja elevou a concentração das frações de nitrogênio total solúvel, insolúvel, amídico e amônia, segundo EATON (1949). Este autor sugere que a deficiência de fósforo resultou em proteolise nas fôlhas inferiores e prejudicou a resíntese.

Os tratamentos que afetaram a concentração de fósforo nas fôlhas quando contrastados com o Completo foram o $-\mathrm{P}$ e o $-\mathrm{N}$ o primeiro diminuindo e o segundo aumentando. Os outros tratamentos não apresentaram diferença estatística em relação ao Completo.

O aumento do teor de fósforo onde se produziu a deficiência de nitrogênio concorda com a observação de CLEMENTS e outros (1941) e HAAG (1965) em cana-de-açúcar. JENNING (1963) citando o experimento de Ketchum comenta que o nitrato pode incrementar a incorporação de fosfatos nos compostos orgânicos, como também, favorecer a síntese do carregador responsável pela absorção de fósforo. Em condições de deficiência de nitrogênio o fosfato não seria fixado nos compostos orgânicos e, daí, possìvelmente, a tendência desse nuntriente em se translocar para os órgãos mais velhos onde a falta de nitrogênio altera o equilíbrio iônico. 
Os contrastes entre os teores de potássio nas fôlhas revelam que os tratamentos $-\mathrm{K},-\mathrm{Ca},-\mathrm{S},-\mathrm{P}$ e $-\mathrm{Mg}$ diferiram do completo. Este último não diferiu somente do -N. A Omissão do magnésio, cálcio, enxôfre e fósforo favoreceram o acúmúlo de potássio. A absorção de potássio pelas raízes está relacionada à absorção de outros ions. A diminuição na absorção de um cation será compensada pela absorção de outro de modo que o total de bases permanecerá constante (HOAGLAND, 1948).

DIBES e SAMUELS (1957) verificaram que nos tratamentos sem fósforo ou enxôfre o teor de potássio era mais elevado. Observaram ainda uma diminuição da concentração de potássio quando foi omitido o nitrogênio. Os dados obtidos neste experimento de um modo geral, mostram-se concordantes com os observados por aqueles autores.

A concentração de cálcio nas fôlhas foi menor, em relação ao Completo, nos tratamentos onde se omitiu o cálcio, nitrogênio, fósforo e magnésio da solução nutritiva. Por outro lado, o tratamento completo não diferiu dos tratamentos $-\mathrm{S}$ e $-\mathrm{K}$. O tratamento mostra-se quase no limite da diferença mínima significativa de modo a indicar um acúmulo de cálcio relacionado com deficiência de potássio. Isto evidencia novamente a proposição do equilíbrio de bases sugerida por HOAGLAND (1948).

OVERSTREET e outros (1952) afirmam que o potássio e o cálcio são absorvidos por um mecanismo semelhante e que outros cations pelo mesmo ponto do carregador de modo que a falta de um resultou na maior absorção do. outro.

A omissão do nitrogênio ou fósforo ocasionou um efeito depressivo na absorção de cálcio.

A concentração de magnésio nas fôlhas não apresentou diferença significativa a $5 \%$ entre os tratamentos Completo, $-\mathrm{P},-\mathrm{N},-\mathrm{S}$ e -K. Entretanto, onde se omitiu o cálcio achou-se um teor significativamente mais elevado que nos demais tratamentos. $\mathrm{O}$ acúmulo de magnésio no tratamento - Ca pode ser explicado como devido à falta de cálcio na solução nutritiva.

Excetuando o tratamento $-\mathrm{N}$ os restantes não diferiram do tratamento Completo, no que concerne ao teor de S, embora as fôlhas mostrassem sintomas de deficiência desse nutriente o que pode ser atribuído ao elevado teor acumulado por ocasião do desenvolvimento inicial das plantas em solução completa. Deve-se frisar que as análises químicas se referem ao teor de cada elemento encontrado nas fôlhas e os sintomas de deficiência se manifestaram nas fôlhas novas. Estas foram reunidas em cada repetição com as restantes em virtude da quantidade ser insuficiente para análise. 
As fôlhas apresentaram maior número de variações nos teores quando comparados com os das raízes e dos caules.

A figura 4.1 mostra que o nitrogênio elevou-se nos tratamentos $-\mathrm{P},-\mathrm{K},-\mathrm{Ca}$ e $-\mathrm{Mg}$. O fósforo revelou êste fenômeno somente para o -N. De mesmo modo, o potássio também elevou-se nos tratamentos $-\mathrm{P},-\mathrm{S},-\mathrm{Mg}$ e $-\mathrm{Ca}$. Nos tratamentos $-\mathrm{P},-\mathrm{N}$ e $-\mathrm{Mg}$, o cálcio revelou diminuir a concentração. No tratamento $-\mathrm{N}$ verifica-se que houve um aumento da concentração de enxôfre nas folhas.

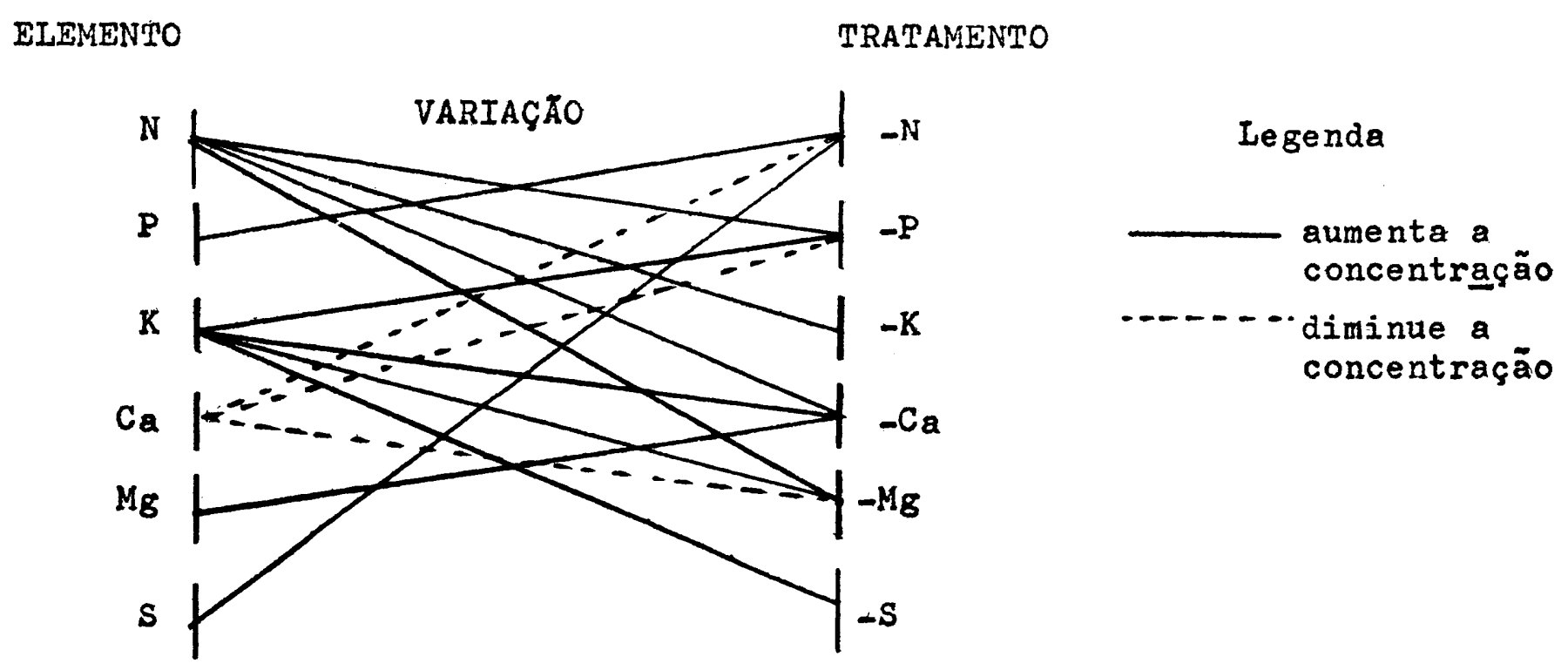

\section{CONCLUSÕES}

O presente trabalho teve o propósito de estudar, preliminarmente, alguns aspectos da nutrição mineral do feijoeiro (Phaseolus vulgaris L., var. roxinho) no que concerne : a sua exigência mineral dos macronutrientes em condições de campo; o efeito da omissão destes nutrientes, em solução nutritiva, nas alterações morfológicas, alterações anatômicas, produção de matéria verde e seca e a sua composição mineral.

Para verificar as necessidades minerais do feijoeiro foi instalado um ensaio de campo com 2 repetições adubadas, nas quais eram colhidas amostras representativas contendo 100 plantas cada uma de cada repetição, em intervalos de 10 dias a partir do $15 .^{\circ}$ dia após o plantio. $\mathrm{O}$ material obtido, verde e seco, e a análise química permitiram concluir :

1. A maior produção de material verde e séco ocorreu em torno de 56 dias após o plantio, revelando nesse período, uma correlação 
positiva (ao nível de 1\%) entre a matéria seca e a idade. Este fato foi observado também em relação a raiz, caule e fôlhas.

2. As quantidades de elementos (em $\mathrm{kg} / \mathrm{ha}$ ) retirados pela cultura durante o ciclo vegetativo foram de : 101,6 de N; 92,6 de K ; 54,1 de $\mathrm{Ca} ; 25,4$ de $\mathrm{S} ; 17,7$ de $\mathrm{Mg}$ e 9,1 de $\mathbf{P}$.

3. As quantidades exportadas pelas sementes foram de : $\mathrm{N}-37,2$, $\mathrm{P}-22,0, \mathrm{~S}-9,5, \mathrm{Ca}-4,4, \mathrm{Mg}-4,4$, e P-3,6kg/ha.

Para verificar os efeitos da omissão dos macronutrientes, plantas de feijoeiro com 15 dias de idade foram transplantadas para solução nutritiva completa e deficiente em condições controladas.

A colheita foi executada quando os sintomas de carência se mostraram evidentes, procedendo-se a descrição morfológica e anatômica das deficiências, e, também, a separação em raizes, caules e fôlhas que forneceram o peso do material verde e seco e o teor de cada macronutriente. Os dados obtidos permitiram as conclusões que seguem :

4. A omissão de nitrogênio, fósforo, potássio, cálcio, magnésio e enxôfre resultou na apresentação de sintomas morfológicos de deficiências características a cada elemento.

5. As principais alterações anatômicas na fôlha foram as modificações do cloroplasto no tamanho e na forma, devido a omissão do nutriente.

6. A produção de matéria seca foi afetada pelos tratamentos na seguinte ordem decrescente : $-\mathrm{S},-\mathrm{K},-\mathrm{Mg},-\mathrm{Ca}-\mathrm{P}$ e $-\mathrm{N}$.

7. A análise química revelou que omitindo um nutriente ocorre uma diminuição do teor do mesmo nos órgãos estudados, quando comparado com o tratamento completo.

8. As principais interações entre os elementos nas fôlhas foram as seguintes: o teor de nitrogênio aumentou no tratamento $-\mathrm{P},-\mathrm{K}$, $-\mathrm{Ca}$ e $-\mathrm{Mg}$; o fósforo no $-\mathrm{N}^{\prime}$; o potássio nos tratamentos $-\mathrm{P},-\mathrm{S}$, $-\mathrm{Mg}$ e $-\mathrm{Ca}$; o enxôfre aumentou no $-\mathrm{N}$; o cálcio diminuiu nos tratamentos $-\mathrm{P},-\mathrm{N}$ e $-\mathrm{Mg}$.

\section{SUMMARY}

\section{STUDIES ON THE MINERAL NUTRITION OF THE BEAN PLANT (PHASEOLUS VULGARIS L., VAR. ROXINHO)}

6.1. The uptake of macronutrients by bean plants was studied under field conditions. It was shownthat higher production of dry matter was obtained when the crop was 56 days old. Total amounts absorved were, in $\mathrm{kg} / \mathrm{ha}: \mathrm{N}-101, \mathrm{P}-9, \mathrm{~K}-93, \mathrm{Ca}-54, \mathrm{Mg}-18$ and S-25. 
6.2. When grgown in nutrient solution symptoms of deficiency were observed for all nutrients under study. Anatomical lesions within the leaf tissue were also observed, the chloroplasts being particularly affected. The following leaf levels of elements in the dry leaves characterize conditions of deficiency: $\mathrm{N}-1.54 \%, \mathrm{P}-0.13 \%, \mathrm{~K}-0,93 \%$, $\mathrm{Ca}-0.42 \%, \mathrm{Mg}-0.48 \%, \mathrm{~S}-0.70 \%$.

\section{LITERATURA CITADA}

COBRA NETTO, A., W. R. ACCORSI, T. COURY, E. MALAVOLTA, E, C. FERRAZ. 1963. Sintomas de deficiências e alterações anatômicas nas fôlhas e raizes do fejoeiro devidos à falta de potássio. IX Congresso Brasileiro de Ciências do Solo - Fortaleza - Ceará.

CHAPMAN, H. D. 1966. Calcium. In: Diagnostic criteria for plants soils Ed. H. D. Chapman University of California. Division of Agricultural Sciences.

CIBES, H. e G. SAMUELS.. 1957. Mineral deficienc symptons displayed by coffee trees under controled conditions. Agricultural Experiment station, University of Puerto Rico, Rio Piedras, P. R. Techn. Paper 14.

CIBES H. e G. SAMUELS. 1957. Mineral deficiency symptons displayed by deficiency by tobacco grown in the greenhouse under controlled conditions. Agricultural Experiment Station. University of Puerto Rico. Rio Pie. dras. P. R. Techn. Paper 23.

JENNINGS, D. H. 1963. The absorption of solutes by plants cells. Ed. Oliver St. Boyd. Edinburgh, Londres.

EATON, S. U. 1952. Effects of potassium deficiency on growtha and metabolism of tomato. Botany ciazzete, 112:300.

EATON, S. U. 1949. Effects of phosphourus deficiency on growth and metabolısm of suntlower. The Botanical Gazette 110:438.

GALLO, J. R. e S. MIYASAKA. 1961. Composição química do feijoeiro e absorção de elementos nutritivos do florescimento à maturação. Bragantia 20:867.

DESAI, M. C. 1937. Effect of certain nutrient deficiences on stomatal behavior. Plant Physiology 12:253.

GILBERT, F. A. 1951. The place of sulfur in plant nutrition Botany Revue $17(9): 671$.

HOAGLAND, D. R. e D. I. ARNON. 1950. The water culture method for growing plants without soil California Agricultural Experiment Station California. Circ. 347.

HAAG, H. P. et all. 1967. Absorção de nutrientes pela cultura do feijoeiro (Phaseolus vulgaris L., var. Chumbinho opaco) (em impressão).

HAAG, H. P. 1958. Efeitos das deficiências e excessos de macronutrientes no crescimento e na composição do cafeeiro (Coffea arabica L., var. bourbon (B. Rodr.) Choussi), cultıvado em solução nutritıva. Tese mimeografada. E. S. A. "Luiz de Queiroz", U. S. P. Piracicaba, E. São Paulo.

HAAG, H. P. 1956. Estudos de nutrição mineral da cana-de-açúcar (Saccharum officinarun L. variedade CB 41-76) cultivado em solução nutritiva. Tese mımeogrataaa. E. S. A. "Luız de Queıroz", U. S. P. Piracicaba - São Paulo.

HOAGLAND, D. R. 1948. Lectures on the inorganic nutrition of plants 2 th ed. Puol. by the chronica Botanica Company. Waltham, Massachussets. 
MALAVOLTA, E. 1971. Nutrição Mineral do feijoeiro I. Simp. Bras. Feijão (Campinas, agôsto 1971): 1-39.

NEAS, I. 1953. Sulphur nutrition in fluecured tobacco. Agronomy Journal $45(10): 472$.

OVERSTREET, R., L. JACOBSON e R. HANDLEY. 1952. The effect of calcium an the absorption of potassium by barley Plant Physiology, 27:583.

RANZANI, G. et all. (1966). Carta de solos do Município de Piracicaba. Centro de Estudos dos Solos. E. S. A. "Luiz de Queiroz" Piracicaba.

RICHARDS, E. J. e E. BERNER. 1954. Physiological studies in plant nutrition. XVII. A general survey of the free aminoacids of barley as effected by mineral nutrition with special reference to potassium supply. Annals of Botany 18:15.

RICHARDS, E. J. e W. G. TEMPLEMAN. 1936. Phy siological studies implant nutrition. IV nitrogen metabolism in relation to nutrient deficiency and age in leaves of barley. Annals. Botany 50:367.

SUZUKI, K. e M. KENJO. 1936. The water culture experiments of sugar cane plant. Part. 2. The potassium deficiency experiments. Rept. Govt. Sug. Exp. Sta. Taiman. Formosa.

ULRICH, A. e K. OHKI. 1966. Potassium. In. Diagnostic criteria for planta \& Soils. Ed. H. D. Chapman University of California. Division of Agricultural Sciences.

WALL, M. E. 1939. The sole of potassium in plants. I. Effects of varying smounts of potassium on nitrogenis. Carbohychate and mineral metabolism in the tomato plant. Soll Science, 47:143.

WALLACE, T. 1961. The diagnosis of mineral deficiencies in plants. Her Majesty's Stationery Office, London. pag. 85. 